\section{SS THEMA}

\title{
A Utilização de Materiais Alternativos no Ensino de Química no Conteúdo de Geometria Molecular
}

\section{The Use of Alternative Materials in Chemistry in the Content of Molecular Geometry}

Malena Gomes Martins ${ }^{1}$; Geraldo Fernando Gonçalves de Freitas ${ }^{1}$; Pedro Hermano Menezes de Vasconcelos ${ }^{1}$

\section{RESUMO}

A Química costuma ser apresentada ao aluno apenas por quadro, pincel e livro didático, e muitas vezes este sente dificuldade de compreender certos conteúdos como, por exemplo, é o caso de Geometria Molecular, que exige do estudante uma visualização de moléculas em três dimensões. Como diversas escolas do país não possuem laboratórios equipados, sejam eles de ciências ou de Informática, a utilização de materiais alternativos é uma potencial forma de dinamizar o conteúdo e aproximá-lo dos estudantes. Após ser desenvolvida uma atividade sobre o conteúdo de Geometria Molecular, foi aplicado um questionário aos participantes, onde estes citam suas principais dificuldades vivenciadas na sala de aula e como a utilização dos materiais alternativos na construção de um modelo molecular auxiliaria na aprendizagem, principalmente se for construído com materiais de baixo custo.

Palavras-chave: materiais alternativos, química, ensino.

\begin{abstract}
Chemistry is usually presented to the student only by painting, brush and didactic book, and often this one finds difficulty to understand certain contents as, for example, is the case of Molecular Geometry, that requires of the student a visualization of molecules in three dimensions. As several schools in the country do not have equipped laboratories, whether in science or computer science, the use of alternative materials is a potential way to streamline content and bring it closer to students. After an activity was developed on the Molecular Geometry content, a questionnaire was applied to the participants, where they cite their main difficulties lived in the classroom and how the use of alternative materials in the construction of a molecular model would aid in learning, especially if it is built with low cost materials.
\end{abstract}

Keywords: alternative materials, chemistry, teaching.

\footnotetext{
${ }^{1}$ IFCE - Instituto Federal de Educação, Ciência e Tecnologia do Ceará, Fortaleza/CE - Brasil.
} 


\section{INTRODUÇÃO}

O Ensino de Química costuma ser direcionado por uma estrutura lógica dos conteúdos, o que torna o ensino fragmentado e descontextualizado, dando ênfase apenas a fórmulas e equações, onde a Química é classificada como uma disciplina decorativa relacionada a símbolos, transmitida tradicionalmente com uso apenas do quadro e do livro didático (FILHO et. al., 2011).

Outro fator que pode ser observado é o desinteresse dos estudantes pelo estudo da Química onde em geral isso pode ser influenciado pela falta de atividades experimentais que possam relacionar a teoria e a prática, este problema é devido à falta de laboratório ou de equipamentos que permitam a realização de aulas práticas (PEREIRA, 2013), ou ao próprio preparo do educador.

Um dos motivos agravantes para a não realização das atividades experimentais de Ciências nas instituições educacionais é o alto custo dos materiais, equipamentos laboratoriais e também o fato de alguns educadores se utilizarem destas atividades de forma equivocada, não levando em consideração os importantes indicadores relacionados ao aluno, como o seu conhecimento pessoal dentro da sua perspectiva social e cultural. E por fim terminam não contribuindo para uma aprendizagem significativa, mas sim, para uma mera transmissão de conteúdos (BARBOSA, 2009).

Na maioria das escolas há uma grande dificuldade de se trabalhar a prática nas disciplinas de Ciências, seja por a escola não possuir laboratório ou pela falta de preparo de professores. A falta de experimentos para melhores elucidações de questões teóricas contribui para um senso comum distorcido sobre a disciplina (PEREIRA, 2013).

É de total importância a adequação e colocação das experimentações em um contexto social, visando transcender a simples realização de observações e técnicas, características do ensino das ciências e dos métodos científicos (BARBOSA, 2009). Outra maneira muito importante de facilitar a inserção de práticas no ensino de Química é a utilização de materiais alternativos e de baixo custo.

Para que haja uma aprendizagem significativa em Química, é preciso buscar novos métodos de ensino, se refazer enquanto docente, por exemplo, através de formações continuadas e buscar novas alternativas e recursos inovadores que possibilitem aos educandos criarem seus conceitos, descobrirem novos meios para se chegar a um resultado e aprender de forma dinâmica (FILHO et. al, 2011).

Então, propõe-se a construção de recursos ou materiais de ensino que estabeleçam um elo entre a construção de conceitos químicos e a atividade prática e possa assim melhorar significativamente a aprendizagem do alunado (FILHO et. al, 2011).

Para superarmos as limitações dos laboratórios de nossas escolas que, quando existem são em um pequeno espaço, totalmente desequipado, buscamos desenvolver nas aulas práticas, experimentos de baixo custo, através da utilização de materiais alternativos. As aulas que antes não eram realizadas devido à impossibilidade de recursos materiais são apresentadas aqui como alternativa de superação dessa limitação através do uso do material alternativo (PEREIRA, 2013).

Esses experimentos não precisam ser realizados em laboratórios ou em ambientes especiais, e não estão obrigatoriamente vinculados a materiais especiais, logo eles podem ser realizados com materiais alternativos e de baixo custo em sala de aula (FRANÇA et. al, 2012), ou até mesmo em casa, já que 
a utilização de materiais de baixo custo é acessível e muitos experimentos podem ser realizados com objetos, materiais e reagentes que temos na cozinha

Dessa forma mostra-se de fundamental importância o desenvolvimento de métodos de ensinoaprendizagem de baixo custo, além de uma mudança no próprio docente onde ele se reinventa e assim venha a estimular o aprendizado e possibilitar a compreensão do conteúdo com mais facilidade dessa forma o estudante poderá aprender a química não só na sala de aula, mas também identificála no dia-a-dia, já que isso é o que se busca numa aprendizagem significativa (FRANÇA et. al, 2012).

\section{OBJETIVOS}

- Conhecer as dificuldades dos alunos relacionadas ao conteúdo de Geometria Molecular no Ensino de Química;

- Investigar quais metodologias seriam mais eficientes na aprendizagem do conteúdo de Geometria Molecular;

- Investigar se a utilização de materiais alternativos de baixo custo no ensino de Geometria Molecular seria uma opção de metodologia viável para os alunos por representarem bem as moléculas e aproximarem-se do cotidiano dos alunos.

\section{METODOLOGIA}

A pesquisa foi realizada no Instituto Federal de Educação Ciência e Tecnologia do Ceará - Campus Fortaleza localizado na Avenida 13 (treze) de Maio no Bairro Benfica número 2081, com o intuito de descobrir se os alunos gostariam de ter uma aula de Química com o conteúdo Geometria Molecular ministrada com modelos moleculares confeccionados com materiais alternativos e qual a importância de que esses modelos fossem construídos com materiais alternativos e fossem de baixo custo.

As turmas a qual as aulas foram aplicadas no IFCE pertencem ao Curso Tecnológico em Gestão Ambiental e ao Curso de Tecnologia e Processos Químicos, em ambas as turmas as aulas pertencem à disciplina de Química Geral I do primeiro semestre dos referidos cursos, participaram das aulas um total de 30 (trinta) alunos, 8 (oito) alunos na turma do Curso Tecnológico em Gestão Ambiental e 22 (vinte e dois) alunos na turma do Curso de Tecnologia e Processos Químicos.

As aulas sobre o conteúdo de Geometria Molecular foram ministradas no mesmo dia, mas em horários diferentes para cada turma. A metodologia utilizada na pesquisa foi a Pesquisa-ação. Ao final da aula foi aplicado um questionário aos alunos, os dados foram analisados e catalogados em gráfico e serviram como base para a elaboração deste trabalho.

\section{RESULTADOS E DISCUSSÕES}

Uma das perguntas do questionário aplicado foi para saber qual a maior dificuldade que os alunos sentiram no conteúdo de Geometria Molecular. 


\section{Qual sua maior dificuldade no conteúdo de Geometria Molecular?}

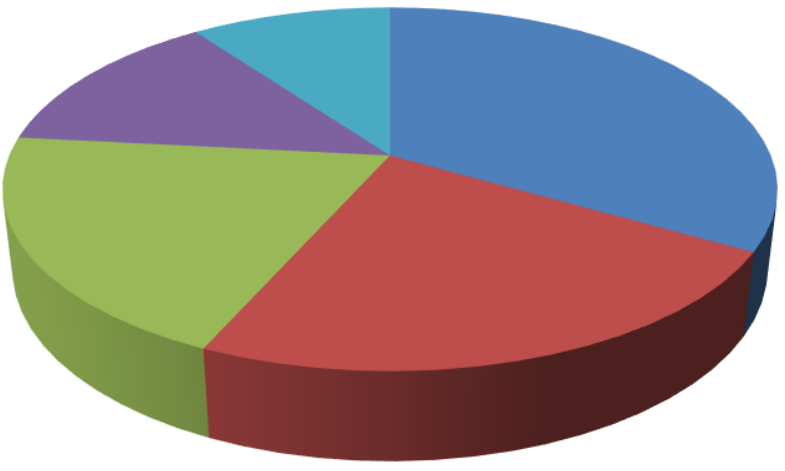

Visualização 33,3\%

Definir o átomo central 23,3\%

- Ângulos de ligação $20 \%$

Elétrons livres 13,3\%

Outros $10 \%$

Gráfico 01: Resposta dos alunos quanto à maior dificuldade no conteúdo de Geometria Molecular.

Como pode ser analisado no gráfico 01 , os alunos ficaram bastante divididos em três principais alternativas, mas a maioria afirmou sentir mais dificuldade em visualizar as moléculas e suas formas geométricas no espaço tridimensional.

Segundo Baptista (2013) a dificuldade de visualização tridimensional dos alunos sempre foi citada pelos professores como um dos principais problemas no aprendizado de Química e provavelmente essa dificuldade esteja atrelada a limitação do uso de recurso por parte do professor, seja por questões metodológicas ou por disponibilidade, as moléculas sempre são mostradas aos alunos apenas com uso de quadro e pincel.

Essa pode ser a causa da maioria dos alunos terem assinalado essa opção já que essa primeira aula foi ministrada apenas com uso de quadro e pincel e as moléculas foram mostradas apenas dessa forma.

A forma de aprendizagem representacional é quando símbolos passam a determinar determinados objetos (MOREIRA, 2012), o que acontece na Geometria molecular, diversas geometrias são representações de figuras como pirâmides, octágonos, gangorra etc. e muitas vezes o aluno não consegue visualizar essas formas apenas com desenhos, gerando assim a dificuldade de compreender o conteúdo.

A segunda pergunta do questionário consistia em saber que tipo de metodologia os alunos gostariam que fosse utilizada numa aula de Geometria Molecular para facilitar a aprendizagem do conteúdo. 


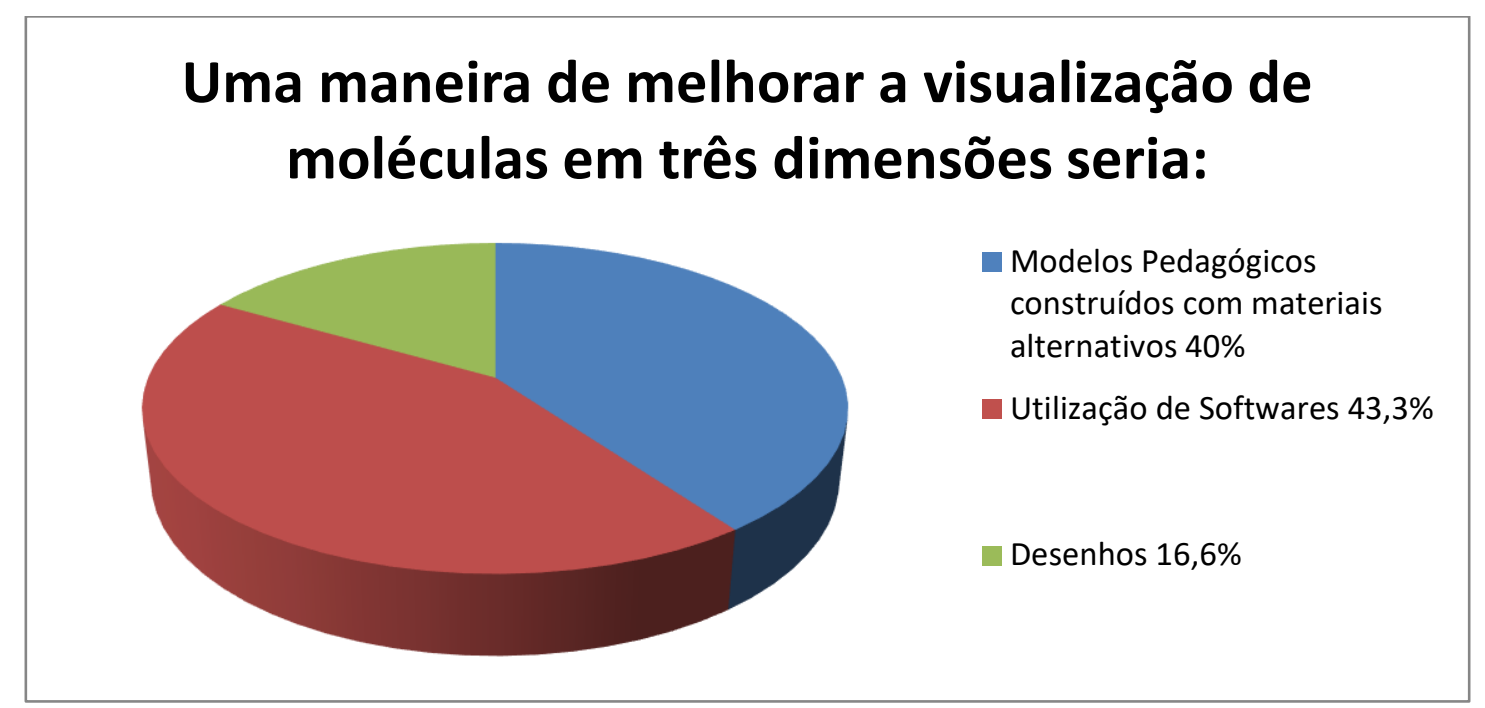

Gráfico 02: Resposta dos alunos quanto à metodologia que gostariam que o professor utilizasse em aula.

Quarenta e três vírgula três por cento afirmaram que gostariam que as aulas fossem ministradas utilizando softwares que os auxiliassem a visualizar a geometria das moléculas em três dimensões e $40 \%$ indicaram que se as aulas fossem ministradas utilizando modelos pedagógicos construídos a partir de materiais alternativos seria mais fácil compreender as geometrias das moléculas e sua disposição no espaço 3D.

Mas a utilização de software pode ficar restrita a algumas escolas devido ao número de computadores não serem suficientes para todos os alunos, softwares muitas vezes possuem licenças pagas e que a escola pública não disponibiliza de recursos para obtê-las e quando é encontrado softwares com licenças livres eles precisam da utilização da internet para funcionar, o que em escolas públicas principalmente localizadas no interior não a possuem com qualidade suficiente para realizar tais atividades

A Organização das Nações Unidas para Educação, Ciência e Cultura (UNESCO) em uma publicação realizada no ano de 2008 sobre o Computador na Escola revela diversas dificuldades encontradas pelos alunos na utilização dos laboratórios de informática durante as aulas, que podem ser desde a falta de computadores ou como o caso de escolas que receberam computadores, mas não possuem internet, o que dificulta caso o professor queira utilizá-lo como uma ferramenta didática durante suas aulas.

Segundo o Instituto Ayrton Senna em um Censo escolar realizado no ano de 2014, 89,9\% das escolas públicas de Ensino Médio possuem laboratório de informática, mas apenas $43 \%$ delas possuem internet de banda larga, o que significa que menos da metade não possuem internet de qualidade e isso prejudica durante uma aula onde todos os alunos terão que acessá-la ao mesmo tempo.

O Censo do Instituto Ayrton Senna (2014) divulga ainda que esse resultado das escolas públicas brasileiras ainda é menor que o das escolas privadas no ano de 2008. Comprovando assim que a escola pública ainda tem muito a melhorar.

O uso de materiais alternativos é como a Aprendizagem Significativa cita uma ótima forma de aproximar o conteúdo do cotidiano do aluno (MOREIRA, 2012), pois muitos desses materiais ele pode ter em casa, pois a cozinha é um laboratório no qual diversas reações acontecem diariamente em um simples preparo de uma refeição. 
A próxima questão era uma pergunta dedicada aos alunos que assinalaram a opção "Modelos pedagógicos construídos com materiais alternativos", eles deveriam responder se o preço desses materiais era importante para que fossem utilizados em sala de aula.

\section{Se você marcou a opção "Modelos Pedagógicos construídos com materiais alternativos", responda: É importante que sejam de baixo custo?}

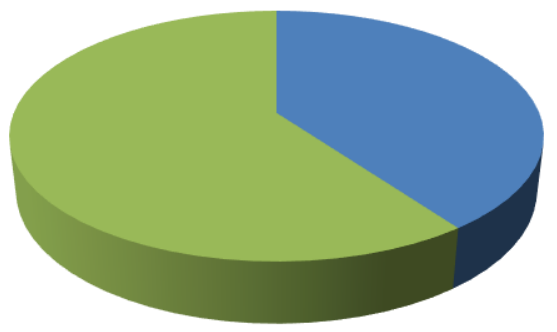

- $\operatorname{Sim} 40 \%$

- Não 0\%

Não responderam $60 \%$

Gráfico 03: Resposta dos alunos quanto à importância do preço dos materiais utilizados na construção dos modelos moleculares.

Conforme pode ser visto no Gráfico 03 todos os alunos que responderam essa questão afirmaram que é de suma importância que os materiais utilizados na confecção dos modelos moleculares sejam de baixo custo.

Algumas estratégias são o uso de modelos físicos para minimizar a dificuldade dos alunos (HUDDLE et. al. 2000). Mas como os modelos disponíveis no mercado possuem custo elevado foi utilizado materiais alternativos, assim o aluno consegue representar as moléculas com um modelo concreto visualizando-as em 3D e ainda utilizando materiais que estão presentes em seu cotidiano, como uma forma de aproximar o conteúdo da realidade do aluno como é citado por Ausubel (1968) na Teoria da Aprendizagem Significativa.

\section{CONCLUSÕES}

Portanto os alunos ao responderem o questionário confirmam que é importante a utilização de materiais alternativos no ensino de Química, especificamente na construção de modelos moleculares de baixo custo para auxiliá-los em uma aprendizagem mais significativa no conteúdo de Geometria Molecular.

Podendo assim diminuir as dificuldades sentidas em relação a visualização das moléculas em três dimensões no espaço, facilitando o nível de abstração quando se é preciso ao visualizar as moléculas em 3D, seus arranjos e ligações, disposição dos átomos e elétrons não ligantes, e proporcionando, portanto, um melhor aprendizado no conteúdo de Geometria Molecular. 


\section{REFERÊNCIAS}

BAPTISTA

M. M. Desenvolvimento

e

Utilização

de

Animações em 3D no Ensino de Química. UNICAMP. Campinas- SP 2013. Disponível em:< http://biq.iqm.unicamp.br/arquivos/770596/br-c1.htm>. Acesso em jan. 2017.

BARBOSA, A. R. JESUS, J. A. A Utilização De Materiais Alternativos Em Experimentos Práticos De Química E Sua Relação Com O Cotidiano. 2009. Disponível em:<http://www.annq.org/congresso2009/trabalhos/pdf/T77.pdf>. Acesso em dez. 2015.

FILHO, F. S. L. et. al. A Importância do uso de Recursos Didáticos Alternativos no Ensino de Química: Uma Abordagem Sobre Novas Metodologias. 2011. Disponível em:<http://www.conhecer.org.br/enciclop/conbras1/a\%20importancia.pdf>. Acesso em jan. 2016.

FRANÇA, M. C. et. al. Recurso Didático Alternativo para Aula de

Eletroquímica.

2012.

Disponível

em:<http://www.santoangelo.uri.br/ciecitec/anaisciecitec/2012/resumos/REL>. Acesso em jan. De 2016.

HUDDLE, P. A. WHITE, M. D. ROGERS, F. Using Teacher Model to Correct know Misconception in Electrochemistry. Jounal of Chemical Education, 77, 104-110. 2000.

Instituto Ayrton Senna. Senso 2014. Disponível em: < http://www.institutoayrtonsenna.org.br/wpcontent/uploads/2015/08/Ayrton_Senna_Institute_2014_Annual_Results_Report.pdf>. Acesso em Jul. 2017.

MOREIRA, M. A. O que é a final aprendizagem significativa? Qurriculum, La Laguna, v. 25, p. 29-56, 2012.

PEREIRA, A. et. al. Uso de Materiais Alternativos em Aulas Experimentais de Química. 2013. Disponível em:<http://www.abq.org.br/cbq/2013/trabalhos/14/3127- 16955.html>. Acesso em jan. 2016.

UNESCO. Computador nas Escolas: Uma Dura Realidade das Escolas. 2008. Disponível em:<http://unesdoc.unesco.org/images/0015/001585/158527por.pdf>. Acesso em fev.2017. 